\title{
Knowledge and Perception of the Risk of Contracting Coronavirus Disease 2019 (COVID-19) among Adult Nigerians
}

\author{
Afocha E. E ${ }^{1}$, Oladele D. $A^{2}$, Ajibaye $O^{3}$, Musa A $Z^{4}$, Ohihoin A. $\mathbf{G}^{2}$, \\ Otuonye N. $\mathbf{M}^{5}$, Igbasi U. $\mathbf{T}^{1}$, David A. $\mathbf{N}^{2}$, Odunukwe N. $\mathbf{N}^{2}$, Audu R. A ${ }^{6}$, \\ Ezechi O. C ${ }^{2}$, Salako B. $\mathrm{L}^{2}$ \\ ${ }^{1}$ Center for Infectious Diseases Research, Microbiology Department, Nigerian Institute of Medical Research, \\ Lagos, Nigeria. \\ ${ }^{2}$ Clinical Sciences Department, Nigerian Institute of Medical Research, Lagos, Nigeria. \\ ${ }^{3}$ Biochemistry Department, Nigerian Institute of Medical Research, Lagos, Nigeria. \\ ${ }^{4}$ Monitoring and Evaluation Unit, Nigerian Institute of Medical Research, Lagos, Nigeria. \\ ${ }^{5}$ Central Public Health Laboratory, Nigerian Institute of Medical Research, Lagos, Nigeria. \\ ${ }^{6}$ Center for Human Virology, Microbiology Department, Nigerian Institute of Medical Research, Lagos, \\ Nigeria.
}

Corresponding Author: Oladele, David Ayoola

\begin{abstract}
The Coronavirus disease 2019 (COVID-19) is considered a major public health challenge of this century. The disease caused by the virus, severe acute respiratory syndrome coronavirus 2 (SARSCoV-2) has resulted in a pandemic that has caused severe morbidity and mortality globally including Africa with the limited ability of requisite public health response. Therefore, this survey aims to assess the knowledge and risk perception of COVID-19 among the general public in Nigeria following an index case confirmation in the country. This is an online cross-sectional survey among the general adult population in Nigeria aged 18 years and above. Study variables were summarized using descriptive statistical methods while bivariate analysis was done to determine the association between socio-demographic characteristics of the respondents and outcome variables. Out of 254 respondents who participated in this study, (50.6\%) were males and (49.4\%) were females. The most stated source of information on COVID-19 was social media (88.5\%). More than half (69.3.\%) had good knowledge of COVID-19, less than one-third (26.0 \%) had average knowledge while just a few had poor knowledge $(4.7 \%)$ of the disease. Risk perception among the respondents was low and evenly distributed. There was no statistically significant association between, education, gender, and employment status of the respondents and good knowledge of COVID-19. The study suggests that a considerable proportion of respondents have adequate knowledge and awareness related to COVID19. However, respondent's risk perception of contracting the disease was low. There is a need therefore for robust enlightenment through effective behavioral change communication campaigns.
\end{abstract}

Keywords: Knowledge, Perception, Risk, COVID-19, Nigeria.

\section{INTRODUCTION}

In December 2009, in Wuhan city, Hubei province, China, a novel coronavirus disease, named coronavirus disease 2019 (COVID-19) was first identified in patients with the severe respiratory disease ${ }^{[1]}$. Since then, it has been claiming thousands of lives every day globally, consequently, resulting in one of the major public health problems of this century as well as one of the largest global health crises in modern history. As a result, the World Health Organization (WHO) declared COVID-19 a pandemic on 11th of March $2020^{[2]}$ having produced one 
of the largest global health crises in modern history. The Pandemic has shut down major cities around the world, leading to unprecedented global travel restrictions. The etiology of COVID-19 is a novel coronavirus named scientifically as severe acute respiratory syndrome coronavirus 2 $(\mathrm{SARS}-\mathrm{CoV}-2)^{[3,4]}$.

As of $21^{\text {st }}$ October 2021, there has been 241,568,522 confirmed cases worldwide, including 4,913,106 deaths. In Africa, there has been 8,521,000 cumulative cases with 216,000 deaths while in Nigeria, 209,713 cases have been confirmed with 2,840 deaths [5,6,7], with Lagos as the epicenter. The disease has the potential to spread easily and can cause severe disease in adults especially older people and patients with co-morbidities ${ }^{[8,9]}$.

Human to human transmission of SARS-CoV-2 occurs when huge respiratory droplets are produced by persons infected with SARS-CoV-2, mainly by coughing, talking, singing, and sneezing, which then get in touch with the nose, mouth, or eyes of another person, or when they are inhaled. Although these huge respiratory droplets are too heavy to be airborne, they possibly can settle on lots of environmental surfaces, such that infection can easily be transmitted by hands getting in contact with contaminated objects, materials, and/or surfaces and then touching the eyes, nose, or mouth ${ }^{[10,11]}$. In critical circumstances, the virus causes deadly pneumonia which resembles the one caused by severe acute respiratory syndrome coronavirus (SARS$\mathrm{CoV})$, and Middle East respiratory syndrome coronavirus (MERS-CoV), ${ }^{[12]}$.

Anxiety regarding the virus across the globe had become greater following its soaring transmission rate, in addition to morbidity and mortality ${ }^{[3]}$. The aged and patients with underlying illnesses have higher possibilities of getting infected and are also more likely to have severe complications, which may be because of acute respiratory distress syndrome (ARDS) and cytokine storm ${ }^{[9]}$.
In Nigeria, the first case of Covid-19 was reported on $27^{\text {th }}$ February 2020, when an Italian citizen in Lagos tested positive for the virus ${ }^{[13,14]}$. Subsequently, a series of public health measures including case detection, contact tracing, and quarantine, counsel, and information to the public was applied and intensified by the Federal Government of Nigeria (FGN) through the Federal Ministry of Health (FMoH) and the Nigerian Center for Disease Control (NCDC). Information to the public was provided through sensitization campaigns using different ways of communication, like Radio, television, social media, and mobile text messages, to inform the populace about the disease. In addition, other containment master plans such as the closure of schools, land borders, and airspaces, inter-state travel restrictions, suspension of public gatherings, enforcement of nighttime curfew, and declaration of total lockdown has also been adopted to slow the spread.

Insight from the SARS outbreak in 2003 in China, indicates that awareness towards infectious diseases is related to the extent of nervousness among the populace, which can in addition muddle efforts to prevent the spread of the disease [15]. Actions such as underrating, stigmatization, nervousness, and negative measures to prevent infection affect efforts aimed at disease control ${ }^{[16]}$. Bearing in mind that various social implications of the COVID19 pandemic are piloted by behavioral decisions like hygiene practices and social distancing, understanding knowledge and perception related to COVID-19 can be helpful in advising public health professionals and policymakers on ways to develop effective behavior change communication campaigns and targeted intervention.

Thus, to guarantee compliance with these measures and expedite the prevention and management of COVID-19 in Nigeria, there is an immediate need to comprehend people's knowledge and perceptions towards the disease, as well as its severity. Therefore, this study aimed to 
evaluate the knowledge and risk perception of COVID-19 among the general adult public in Nigeria.

\section{METHOD}

\subsection{Study Design and Population}

This was a cross-sectional survey of the general public in Nigeria. The targeted population for the survey was adults aged 18 years or older presently living in Nigeria. The study was conducted from $6^{\text {th }}$ April to $12^{\text {th }}$ June 2020 through an online survey.

\subsection{Study Tool}

English Language, the official language in Nigeria was used to design the survey questionnaire, which covered the socio-demographic characteristics, knowledge of COVID-19, knowledge regarding symptoms, spread, prevention, and treatment of the disease, as well as risk perception of the disease.

\subsection{Validation and Pilot Study}

The questionnaire was pilot tested among the survey team members and the estimated completion time of the survey was 7-10 minutes.

\subsection{Data Collection}

Google Form was created for the online survey portal. Participants were invited to participate in the study by completing and submitting the form. The survey questionnaire (Appendix I) was shared via social media platforms (WhatsApp, Facebook, and Twitter). Informed consent was obtained, and an eligibility assessment was done before participants could complete the questionnaire.

\subsection{Statistical Analysis}

Data on socio-demographic characteristics as well as answers to questions relating to knowledge and risk perception towards COVID-19 were summarized using Descriptive statistics. In general, knowledge of respondents to COVID-19 was classified as good $(\geq 80 \%)$, average $(65-79 \%)$, and poor $(<65 \%){ }^{[17]}$. For categorical variables, data were summarized as frequencies (n) and percentages (\%). Bivariate analysis was done to determine the association between socio-demographic characteristics of the respondents and outcome variables.

\subsection{Ethical Considerations}

Ethical approval for the survey was sought and obtained from the Nigerian Institute of Medical Research Institutional Review Board.

\section{RESULTS}

The total number of respondents who participated in the study were 254 . These participants were majorly within the age group of 35 to 44 years (36.8\%) and 25 to 34 years $(30.7 \%)$ with the mean age of 36.3 years. About half of the participants were males (50.6\%). Respondents were also well educated as almost all (97.2\%) had tertiary education and more than three quarters (80.0\%) were employed (Table 1$)$.

Table 1: Socio-demographic characteristics of the respondents
\begin{tabular}{|l|l|l|}
\hline Variables & Frequency & Percent \\
\hline Age (n=228) & & \\
$<25$ & 32 & 14.0 \\
$25-34$ & 70 & 30.7 \\
$35-44$ & 84 & 36.8 \\
$45-54$ & 31 & 13.6 \\
$\geq 55$ & 11 & 4.8 \\
\hline Sex (n=253) & & \\
Female & 125 & 49.4 \\
Male & 128 & 50.6 \\
\hline Education (n=253) & & \\
Secondary & 5 & 2.0 \\
Tertiary & 246 & 97.2 \\
Postgraduate studies & 2 & 0.8 \\
\hline Employment Status $(\mathrm{n}=253)$ & & \\
Employed & 192 & 75.9 \\
Unemployed & 61 & 24.1 \\
\hline
\end{tabular}

Social media was the most stated sources of information (88.5\%), Television (83.0\%), family and friends (66.4\%), while Health worker (45.1\%) was the least stated source of information (Fig. 1). 
Afocha E. E et.al. Knowledge and perception of the risk of contracting coronavirus disease 2019 (COVID-19) among adult Nigerians.

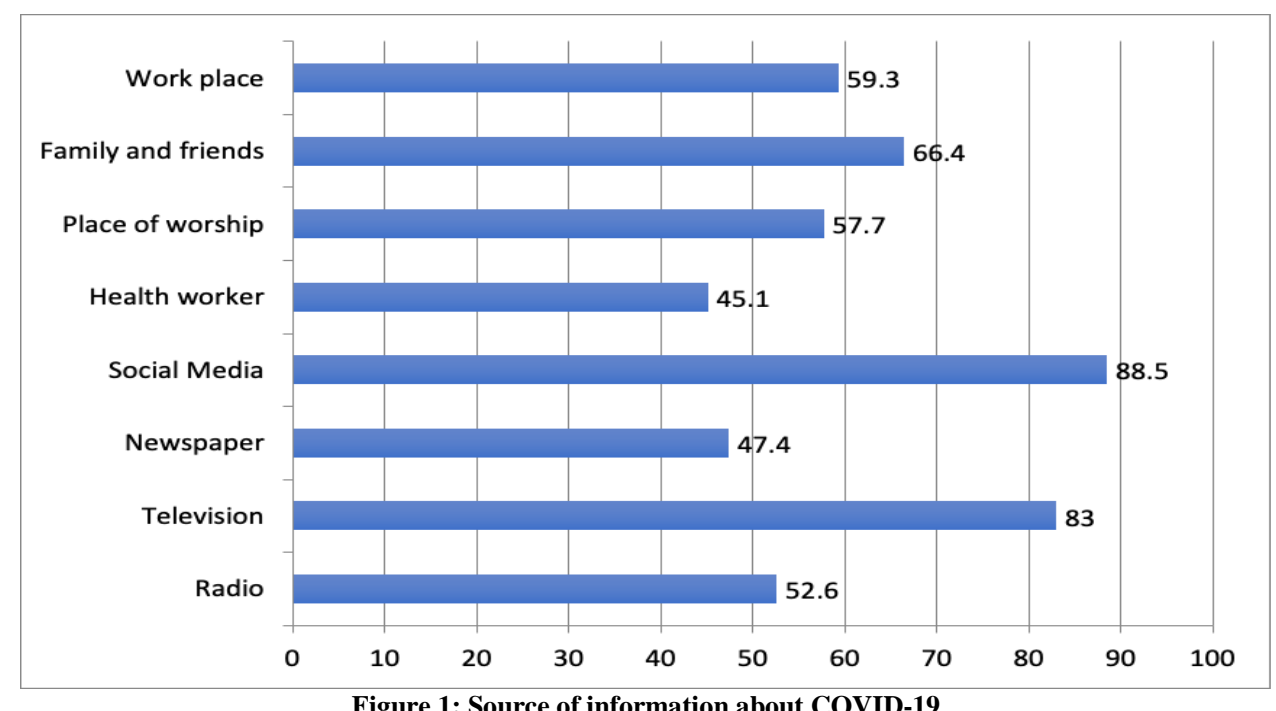

Findings from this study showed that the vast majority of the participants knew that coronaviruses could cause illness in animals and humans (90.1\%) while almost all (96.1\%) of respondents rightly indicated the incubation period of COVID-19. Respondents also had good knowledge of the symptoms of the disease as almost all knew that fever (94.9\%), dry cough (96.1\%), difficulty in breathing (96.9\%) were symptoms of COVID-19. The majority also knew that people who are older and persons with underlying medical problems have a higher possibility of developing serious illnesses $\quad(92.1 \%$ and $84.1 \%$ respectively). Respondents also had a good knowledge of how COVID-19 spreads and fair knowledge on protection against COVID-19 as the majority of them responded positively to the inquired preventive measures. In addition, a vast majority of respondents (91.3\%) also knew that wearing masks can protect against COVID-19. However, more than three quarter $(79.1 \%)$ thinks that the disease can be prevented by taking a vaccine shot. Respondents also had good knowledge regarding the treatment of COVID-19 as most of them $(90.1 \%)$ responded that there is no approved treatment currently (Table 2).

Table 2: Respondent knowledge about COVID-19 disease

\begin{tabular}{|c|c|c|}
\hline+2 & Frequency & Percent \\
\hline $\begin{array}{l}\text { Coronavirus are viruses can cause illness in animals or Humans } \\
\text { Yes } \\
\text { No } \\
\text { Don't know }\end{array}$ & $\begin{array}{l}229 \\
20 \\
5\end{array}$ & $\begin{array}{l}90.1 \\
7.9 \\
2.0 \\
\end{array}$ \\
\hline $\begin{array}{l}\text { How long it takes for an infected person to develop the disease }(\mathrm{n}=254) \\
\text { Immediately } \\
1 \text {-14 days } \\
15-18 \text { days } \\
>18 \text { days }\end{array}$ & $\begin{array}{l}3 \\
244 \\
5 \\
2\end{array}$ & $\begin{array}{l}1.2 \\
96.1 \\
2.0 \\
0.8\end{array}$ \\
\hline $\begin{array}{l}\text { What are the symptoms of COVID-19 }(\mathrm{n}=254) \# \\
\text { Fever } \\
\text { Tiredness } \\
\text { Dry Cough } \\
\text { Sore Throat } \\
\text { Redness of the eyes } \\
\text { Diarrhoea } \\
\text { Nasal Congestion/running nose } \\
\text { Weight loss } \\
\text { Difficulty in breathing } \\
\text { Ache and pain }\end{array}$ & $\begin{array}{l}241 \\
156 \\
244 \\
210 \\
34 \\
83 \\
138 \\
23 \\
246 \\
1 \\
\end{array}$ & $\begin{array}{l}94.9 \\
61.4 \\
96.1 \\
82.7 \\
13.4 \\
32.7 \\
54.3 \\
9.1 \\
96.9 \\
0.4 \\
\end{array}$ \\
\hline $\begin{array}{l}\text { Who is likely to develop serious illness }(n=252) \# \\
\text { Older people } \\
\text { Young people } \\
\text { Children/Infants } \\
\text { Persons with underline medical problems }\end{array}$ & $\begin{array}{l}232 \\
50 \\
70 \\
212\end{array}$ & $\begin{array}{l}92.1 \\
19.8 \\
27.8 \\
84.1\end{array}$ \\
\hline
\end{tabular}


Afocha E. E et.al. Knowledge and perception of the risk of contracting coronavirus disease 2019 (COVID-19) among adult Nigerians.

\begin{tabular}{|c|c|c|}
\hline \multicolumn{3}{|l|}{ Table 2 Continued... } \\
\hline How does COVID-19 spread? $(n=254) \#$ & & \\
\hline Can spread from person to person through small droplets when a person with COVID-19 coughs or exhales, & 251 & 98.8 \\
\hline By touching surfaces, then touching their eyes, nose or mouth & 250 & 98.4 \\
\hline Breathing in droplets from a person with COVID-19 & 230 & 90.6 \\
\hline From the faeces of someone with the disease & 30 & 11.8 \\
\hline Could be caught from a person who has no symptoms, & 150 & 59.1 \\
\hline Pets that have been infected could spread the virus & 67 & 26.4 \\
\hline How to protect yourself against COVID-19 $(\mathrm{n}=254) \#$ & & \\
\hline Maintain at least 3 feet distance between yourself and anyone & 238 & 93.7 \\
\hline Avoid touching eyes, nose and mouth. & 248 & 97.6 \\
\hline Covering with bent elbow/tissue paper when coughing or sneezing. & 242 & 95.3 \\
\hline Staying at home if feeling unwell. & 214 & 84.3 \\
\hline Seek medical advice if develop symptoms & 239 & 94.1 \\
\hline By taking vaccine shot. & 20 & 7.9 \\
\hline Wearing masks & 201 & 79.1 \\
\hline Wearing masks if caring for individuals who have symptoms & 232 & 91.3 \\
\hline Regularly cleaning of hands with an alcohol-based hand rub or wash them with soap and water. & 247 & 97.2 \\
\hline Taking hot bath & 48 & 18.9 \\
\hline Chewing garlic and ginger & 41 & 16.1 \\
\hline How is COVID-19 treated $(\mathrm{n}=253) \#$ & & \\
\hline Use of antibiotics & 19 & 7.5 \\
\hline Use of Chloroquine & 54 & 21.3 \\
\hline Use of HIV drugs & 4 & 1.6 \\
\hline Use of herbal drugs & 5 & 2 \\
\hline No approved treatment currently & 228 & 90.1 \\
\hline
\end{tabular}

\#-Multiple response allowed

Evaluating knowledge of the respondents revealed that more than half (69.3.\%) had good knowledge of COVID19 , less than one third (26.0 \%) had average knowledge while just a few $(4.7 \%)$ had poor knowledge of the disease (Fig, 2).

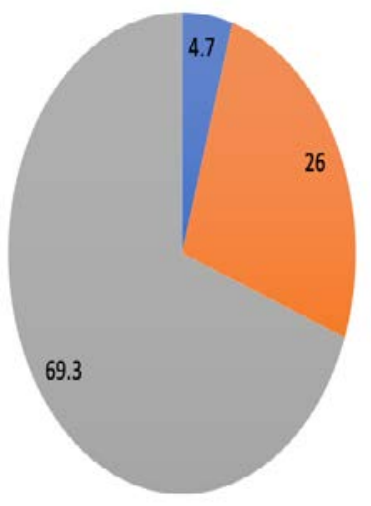

- Poor

Average

$=$ Good

Figure 2: Overall knowledge of COVID-19 among the respondents
Assessment of risk perception among the participants revealed that less than half (41.7\%) were worried and less than a quarter $(22.8 \%)$ were much worried about the disease. Almost half (42.1\%) of the participants believed that they were highly unlikely to acquire the disease compared to less than a quarter (8.3\%) who believed that they were highly likely to acquire the disease. Also, more than three quarters felt most at risk of contracting COVID-19 in public transport (79.9\%) and in public places $(79.5 \%)$. while about half (59.8\%) felt they could contract the disease at work. Almost all respondents (95.6\%) claimed to have changed their infection prevention and control behavior since the onset of the pandemic; $96.0 \%$ claim to wash their hands more frequently while $92.8 \%$ claimed to avoid going to public events (Table 3).

Table 3: Risk Perception to COVID-19 disease among the respondents

\begin{tabular}{|l|l|l|}
\hline Variables & Frequency & Percent \\
\hline How much are you worried about COVID-19 disease & & \\
Not Much & 25 & 9.8 \\
A bit much & 21 & 8.3 \\
Much & 58 & 22.8 \\
Quite much & 44 & 17.3 \\
Very much & 106 & 41.7 \\
\hline Do you think that you have a personal risk of acquiring COVID-19 disease? & & \\
Highly likely & 21 & 8.3 \\
Quite likely & 22 & 8.7 \\
Not Sure & 56 & 22.2 \\
Quite unlikely & 47 & 18.7 \\
Highly unlikely & 106 & 42.1 \\
\hline
\end{tabular}


Afocha E. E et.al. Knowledge and perception of the risk of contracting coronavirus disease 2019 (COVID-19) among adult Nigerians.

\begin{tabular}{|l|l|l|}
\hline \multicolumn{2}{|c|}{ Table 3 Continued... } & 59.8 \\
\hline Where do you feel most at risk of contracting COVID-19 disease (N=249)\# & 149 & 79.9 \\
At work & 199 & 79.5 \\
In public transport & 198 & 57.4 \\
In public places (School, Church) & 143 & 49 \\
At the airport & 122 & 32.1 \\
As a patient in the hospital & 80 & 67.1 \\
In outpatient clinic & 167 & 22.1 \\
During travel to affected country & 55 & 30.9 \\
By food imported from affected country & 77 & 95.6 \\
By other products originating from affected country & 241 & 4.4 \\
\hline Change your behaviour because of the COVID -19 (N=252) & 11 & 96.0 \\
Yes & & 77.3 \\
No & 241 & 92.8 \\
\hline Behaviour changed because of the COVID -19 disease (n=251) \# & 194 \\
I wash my hand more frequently & 233 \\
I avoid contact with people with travel history within14 days. & 147 & 58.6 \\
I avoid going to public events (e.g. football, movie theatre). & & \\
I engaged in precautionary purchases. & 249 & 98.0 \\
\hline Infection control measures practiced by respondents (n=254) \# & 191 & 75.2 \\
Hand washing with soap and water, & 82 & 32.3 \\
Hand Sanitizer, & 191 & 75.2 \\
Face Mask, & 8 & 3.1 \\
Maintaining distance of about one meter, & & \\
Drank herbal concoction &
\end{tabular}

\#-Multiple response allowed

There was a statistically significant association between the age of respondents and knowledge of COVID-19 while gender, education, and employment status of the respondents and their knowledge of COVID-19 were not statistically significantly associated (Table 4).

Table 4: Association between socio-demographic characteristics of respondents and knowledge of COVID-19

\begin{tabular}{|c|c|c|c|c|c|}
\hline \multirow[t]{2}{*}{ Variable } & \multicolumn{3}{|c|}{ Knowledge of COVID-19 } & \multirow[t]{2}{*}{$\mathrm{X}^{2}$} & \multirow[t]{2}{*}{ p-value } \\
\hline & Poor & Average & Good & & \\
\hline $\begin{array}{l}\text { Age } \\
<35 \text { years } \\
\geq 35 \text { years }\end{array}$ & $\begin{array}{l}5(4.9) \\
3(2.4)\end{array}$ & $\begin{array}{l}22(21.6) \\
37(29.1)\end{array}$ & $\begin{array}{l}75(73.5) \\
87(68.5)\end{array}$ & 10.44 & 0.034 \\
\hline $\begin{array}{l}\text { Sex } \\
\text { Female } \\
\text { Male }\end{array}$ & $\begin{array}{l}7(5.6) \\
5(3.9) \\
\end{array}$ & $\begin{array}{l}34(27.2) \\
32(25) \\
\end{array}$ & $\begin{array}{l}84(67.2) \\
91(71.1) \\
\end{array}$ & 1.09 & 0.897 \\
\hline $\begin{array}{l}\text { Education } \\
\text { Secondary } \\
\text { Tertiary } \\
\text { Postgraduate }\end{array}$ & $\begin{array}{l}0(0.0) \\
11(4.5) \\
1(50.0)\end{array}$ & $\begin{array}{l}1(20.0) \\
65(26.4) \\
0(0.0)\end{array}$ & $\begin{array}{l}4(80.0) \\
170(69.1) \\
1(50.0)\end{array}$ & 10.19 & $0.117^{\sharp}$ \\
\hline $\begin{array}{l}\text { Employment } \\
\text { Employed } \\
\text { Unemployed }\end{array}$ & $\begin{array}{l}10(5.2) \\
2(3.3) \\
\end{array}$ & $\begin{array}{l}51(26.6) \\
15(24.6) \\
\end{array}$ & $\begin{array}{l}131 \text { (68.2) } \\
44(72.1)\end{array}$ & 0.98 & 0.913 \\
\hline
\end{tabular}

\section{DISCUSSION}

The rapid spread and introduction of COVID-19 in Africa confirm initially published reports evaluating the readiness and susceptibility of African countries against the importation of COVID-19 ${ }^{[18]}$. The study named Algeria, Egypt, and South Africa as countries with the highest possibility of importing the disease and possess average to high capacity to respond to outbreaks. Conversely, Nigeria, Angola, Ethiopia, Ghana, Kenya, Sudan, and Tanzania, were categorized as average risk and possess the varying capacity and high susceptibility ${ }^{[18]}$. In this study, the results of an online survey about the knowledge, attitude, and perceptions of the Nigerian public towards COVD-19 disease is hereby presented.

Generally, the level of knowledge of respondents is quite moderate as more than half $(69.3 \%)$ of the respondents in this survey demonstrated good knowledge about the COVID-19 disease. Participants who were less than 35 years demonstrated better knowledge of COVID-19 when compared to respondents who were 35 years and above $(\mathrm{p}=0.034)$. However, gender, education, and employment status of the respondents, and their knowledge of COVID-19 was not 
statistically significantly associated. This finding is relatively related to studies carried out in different Asian countries [16,19,20], Egypt, and Kenya [21,22], which showed high knowledge of COVID-19 among the population. However, a study conducted to assess the knowledge and perceptions of COVID-19 among healthcare workers in the United Arab Emirates revealed inadequate knowledge among the population studied ${ }^{[23]}$. Good knowledge of participants on COVID-19 from this study could probably be due to the reason that nearly all the participants (97.2\%) had tertiary education. People who are educated are more likely to read articles, newsletters, and other information on social media on the COVID-19 outbreak. Furthermore, it could be that apparently due to the fact that the disease has no approved treatment, the Nigerian public was anxious and eager to know more about the disease.

An investigation into the source of information on COVID-19 revealed that the main source of information was social media platforms (88.5\%) when compared with other local media platforms; namely newspapers (47.4\%), and radio (52.6\%). This is closely related to studies by Giao et al. and Bhagaythula et al. ${ }^{[19,23]}$ where the majority (77.1\%) and (91.1\%) respectively, received information on the disease through social media. This is not surprising as the internet is easily accessible and an overwhelming majority of Nigerians mostly access the internet through their mobile phones, which allows them to continuously update themselves with relevant information regarding the disease.

Overall risk perception of getting infected with COVID-19 among the respondents was low and evenly distributed with almost half (42.1\%) indicating they were highly unlikely to acquire the disease, which is in contrast with a study by Giao et al. [19] where three-quarters of the participants (82.3\%) believe that they would likely become infected with the illness. The low-risk perception revealed by this study could be attributable to the fact that this study was carried out at the early period during the outbreak of the COVID-19 pandemic in Nigeria when the number of confirmed cases was still quite low. They did not take into cognizance that the low confirmed number of cases could be a result of few testing centers available as at then in the country. Another point of concern was that some Nigerians have the misconception that the virus will not really survive in the country due to the climate, and consequently, will disappear within a short time. This was worsened by the fact that many associated COVID-19 diseases with people who engage in international travel, hence, since the country is in lockdown, the chances of acquiring the disease are very slim. Furthermore, the majority of the participants (81.5\%) were below 45 years old, and apparently healthy without comorbidity and probably assumed that they were at lower risk of acquiring the disease. This was depicted in their response as almost all the participants (92.1\%) identified older people as the people who have a higher probability of developing a severe illness, while the majority $(84.1 \%)$ also identified persons with underlying medical problems at higher risk as well. This further emphasizes the need for policymakers at various levels of government in Nigeria to intensify efforts towards producing rightly targeted interventions and successful behavior change communication campaigns to the populace bearing in mind the weak health care system in the country. Our findings are however similar to published studies about the disease in China where older people with co-morbidities, such as cardiovascular diseases and hypertension, had higher chances of developing an infection than other groups. ${ }^{[24,8]}$.

In our study, concerning the preparedness of the public to prevent getting infected with COVID-19, almost all (98.0\%) of the participants washed hands with soap and water while $75.2 \%$ used hand sanitizers. This is similar to a study by Azlan et $\mathrm{al}^{-[26]}$ which reported that the 
majority of participants (87.8\%) indicated that they practiced proper hand hygiene by washing their hands frequently and making use of hand sanitizers. This high rate of preparedness could be due to the fact that participants' have good knowledge of the disease and the high rate of infectivity of the virus which can be contracted through contaminated hands, objects, and surfaces. Approximately, three-quarters of the participants (75.2\%) practiced social distancing, almost all (96.0\%) washed hands more frequently, the majority (92.8\%) avoided going to public events like football viewing centers and a little over three quarters (77.0\%) avoided contact with people with travel history within 14 days. These high levels of prevention control measures by the participants could be attributable to fear of stigmatization associated with the disease and showed that the participants gave credence to the value of handwashing and restricted personal contact as a means of preventing infection with the virus.

Regrettably, the study revealed that only a little above one-quarter of the participants (32.3\%) wore facemask compared to the vast majority (91.3\%) who knew that wearing of the mask can protect against COVID-19 disease. The reason for this poor use of face mask could probably be attributable to complaints by some people of not feeling comfortable while wearing a face mask, that it is suffocating, while some feel that they and the people around them are apparently feeling fine, not coughing or sneezing, hence, no need of wearing a face mask. This is very worrisome and of great concern as the FGN and NCDC have recommended the use of facemask. In addition, they have provided adequate information on the role of a facemask in mitigating contraction and transmission of the virus. Therefore, it is paramount for concerned authorities to make the public give credence to the existence of asymptomatic carriers and their ability to transmit the virus while emphasizing that in threatening health issues like COVID-19, safety and not comfort should take priority. It further revealed the challenge faced by the FGN, various states, and local governments within the country to implement and enforce strict infection and prevention control (IPC) measures such as compulsory use of facemask.

However, a Chinese study by Zhong et al ${ }^{[16]}$ reported that almost all the participants wore facemasks when they went out during the current pandemic, and a study by Azlan et al. ${ }^{[26]}$ reported that just a little above half of the participants (51.2\%) wore a facemask while in the public. This finding was also not in accordance with the recent WHO and CDC recommendation of putting on cloth face mask by the general public ${ }^{[27]}$. Furthermore, more than three quarter $(79.1 \%)$ believed that the disease can be prevented by taking vaccine shots revealing the misconception surrounding the COVID-19 disease. This could be as a result of fake news trending on social media, reporting unverified and uncertified information concerning the disease. This is worrisome considering the negative impact this could have on mitigating the disease. Government and stakeholders at all levels should intensify the campaign by urging the public not to believe or rely on uncertified fake news trending on social media but rather seek information from certified sources such as WHO, CDC, and NCDC. They should also intensify efforts towards public enlightenment to emphasize that there is no approved vaccine for the disease.

Interestingly, the strength of this study lies in the fact that it provided important information on the knowledge, and risk perception of the Nigerian Public towards contracting COVID-19, which will be very useful in improving the IPC strategies endorsed by the NCDC and FGN to limit the COVID-19 outbreak in Nigeria.

However, it has some limitations arising from the administration of the survey using the internet which permitted only those who are enlightened and have access to the internet to participate in the study. As 
such, underprivileged and unlearned populations of the Nigerian public were not captured in the study.

\section{CONCLUSIONS}

This survey has revealed the need for a robust enlightenment campaign regarding IPC strategies for effective behavioral change to influence compliance with recommendations towards curtailing the COVID-19 pandemic in Nigeria. It further revealed that social media can effectively be used to disseminate information during a suddenly emerging health calamity such as the COVID-19 pandemic and has the ability to acquire much needed empirical data that may be of treasure for the planning, development, and implementation of health communication campaigns to limit threats to health.

\section{RECOMMENDATIONS}

While the government has taken major steps to mitigate the spread of the disease, we recommend that FGN should encourage and enforce the use of facemask. Given that the epidemiology of COVID-19 in Nigeria has transited to the community transmission phase.

\section{ACKNOWLEDGEMENT}

We acknowledge the Nigerian public who participated in this study and our friends who assisted in distributing the questionnaire through social media.

\section{AUTHORS' CONTRIBUTIONS}

AEE and ODA were responsible for the conceptualization of the project. AEE, ODA, AO, and MAZ carried out the Data Collection and Analysis. AEE and ODA wrote the manuscript. OAG, ONM, IUT, DAN, ONN, and ARA reviewed the manuscript. EOC, SBL, AEE, and ODA proofread the final document. The final manuscript has been read and agreed to by all authors.

\section{DECLARATION OF INTERESTS}

The authors declare that they have no conflict of interest.

\section{FUNDING INFORMATION}

The research was funded by Nigerian Institute of Medical Research (NIMR).

\section{REFERENCES}

1. WHO. Coronavirus disease 2019 (COVID19). 2020; situation report, 94.

2. WHO Director-General's opening remarks at the media briefing on COVID-19 11 March 2020. Retrieved April 4, 2020, from https://www.who.int/dg/speeches/detai 1/who-director-general-s-opening-remarksat-the-media-briefing-on-covid-19-11march-2020).

3. Huang, C.; Wang, Y.; Li, X.; Ren, L.; Zhao, J.; Hu, Y.; Zhang, L.; Fan, G.; Xu, J.; Gu, $\mathrm{X}$; et al. Clinical features of patients infected with 2019 novel coronavirus in Wuhan, China. Lancet 2020; 395, 497-506.

4. Zhou, P.; Yang, X.-L.; Wang, X.G.; Hu, B.; Zhang, L.; Zhang, W.; Si, R.H.; Zhu, Y.; Li, B.; Huang, C.-L.; et al. A pneumonia outbreak associated with a new coronavirus of probable bat origin. Nature 2020; 579, 270-273.

5. WHO. Coronavirus COVID-19 Pandemic 2020 from https://www.who.int/emergencies/diseases/n ovel-coronavirus-2019?

6. Coronavirus (COVID-19) WHO Regional Office for Africa from https://www.afro.who.int/healthtopics/coronavirus-covid-19

7. NCDC Coronavirus COVID-19 Microsite available at https://covid19.ncdc.gov.ng/

8. Guan W.J., Liang W.H., Zhao Y., Liang W.H.R., Chen Z.S., Li Y.M. China Medical Treatment Expert Group for Covid-19. Comorbidity and its impact on 1590 patients with Covid-19 in China: a nationwide analysis. Eur. Respir. J. 2020; 55 (5): 2000547 doi: 10.1183/13993003.005472020 [PMC free article] [PubMed] [CrossRef] [Google Scholar]

9. Guo, Y. R., Cao, Q. D., Hong, Z. S., et al. The origin, transmission and clinical therapies on coronavirus disease 2019 (COVID-19) outbreak - an update on the 
status. Military Medical Research. 2020; $7(1), 11$.

10. The World Health Organization Q\&A on coronaviruses (COVID-19). Retrieved April 4, 2020, from https://www.who.int/newsroom/q-a-detail/q-a-coronaviruses.

11. Coronavirus Disease 2019 (COVID-19) from

https://www.cdc.gov/coronavirus/2019-

ncov/hcp/non-us-

settings/overview/index.html

12. Li, Y. C., Bai, W. Z., \& Hashikawa, T. The neuroinvasive potential of SARS-CoV2 may play a role in the respiratory failure of COVID-19 patients. Journal of Medical Virology 2020; https://doi.org/10.1002/jmv.25728.

13. First Case of Corona Virus Disease Confirmed in Nigeria". Nigeria Centre for Disease Control. 28 February 2020.

14. Maclean, Ruth; Dahir, Abdi Latif. "Nigeria Responds to First Coronavirus Case in SubSaharan Africa". The New York Times. (28 February 2020).

15. Hung, L. S. The SARS epidemic in Hong Kong: What lessons have we learned? Journal of the Royal Society of Medicine. 2003; 96(8), 374-378.

16. Zhong B, Luo W, Li H, Zhang Q, Liu X, Li $\mathrm{W}$ et al. Knowledge, attitudes and practices towards COVID-19 among Chinese residents during the rapid rise period of the COVID-19 outbreak: a quick online crosssectional survey. Int J Biol Sci. 2020; Mar 15;16(10):1745-1752. PubMed | Google Scholar

17. Engelbrecht, M., Janse van Rensburg, A., Kigozi, G., Van Rensburg, HD. (2016). Factors associated with good TB infection control practices among primary healthcare workers in the Free State Province, South Africa. BMC infectious diseases, 16(1),633 https//doi.org/10.1186/s12879-016-1984-2

18. Gilbert M, Pullano G, Pinotti F, Valdano E, Poletto C, Boëlle PY et al. Preparedness and vulnerability of African countries against importations of COVID-19: a modelling study. Lancet. 2020; 395(10227):871877. PubMed | Google Scholar

19. Giao H, Nguyen TNH, Tran VK, Vo KN, Vo VT, Pham LA. Knowledge and attitude toward COVID-19 among healthcare workers at District 2 Hospital, Ho Chi Minh City. Asian Pacific Journal of Tropical
Medicine. 2020; doi: 10.4103/19957645.280396. [CrossRef] [Google Scholar]

20. Saqlain M, Munir MM, Rehman S, Gulzar A, Naz S, Ahmed Z, Tahir AH, Mashhood M. Knowledge, attitude, practice and perceived barriers among healthcare professionals regarding COVID-19: A Cross-sectional survey from Pakistan. Journal of Hospital Infection. 2020; 105:419-423. doi: 10.1016/j.jhin.2020.05.007. [CrossRef] [Go ogle Scholar]

21. Abdelhafiz AS, Mohammed Z, Ibrahim ME, Ziady HH, Alorab M, Ayyad M, Sultan EA. Knowledge, perceptions, and attitude of Egyptians towards the novel coronavirus disease (COVID-19). Journal of Community Health. 2020; doi: 10.1007/s10900-02000827-7. [PMC free article] [PubMed] [CrossRef] [Google Scholar]

22. Austrian K, Pinchoff J, Tidwell JB, White C, Abuya T, Kangwana B. COVID-19 related knowledge, attitudes, practices and needs of households in informal settlements in Nairobi, Kenya. Bulletin of World Health Organization. 2020 doi: 10.2471/BLT.20.260281. [CrossRef] [Googl e Scholar]

23. Bhagavathula AS, Aldhaleei WA, Rahmani J, Mahabadi MA, Bandari DK. Novel coronavirus (COVID-19). knowledge and perceptions: a survey on healthcare workers. medRxiv. 2020; Google Scholar

24. Li, L. Q., Huang, T., Wang, Y. Q., et al. Novel coronavirus patients' clinical characteristics, discharge rate, and fatality rate of meta-analysis. Journal of Medical Virology. 2020; 17. https://doi.org/10.1002/jmv.25757.

25. Liang, W., Guan, W., Chen, R., et al. Cancer patients in SARS-CoV-2 infection: A nationwide analysis in China. The Lancet Oncology. 2020; 21(3), 335337. https://doi.org/10.1016/S14702045(20)30096-6.

26. Azlan AA, Hamzah MR, Sern TJ, Ayub SH, Mohamad E. Public knowledge, attitudes and practices towards COVID-19: A crosssectional study in Malaysia. PLoS ONE. 2020;15(5): e0233668. doi: 10.1371/journal.pone.0233668. [PMC free article] [PubMed] [CrossRef] [Google Scholar]

27. Recommendation Regarding the Use of Cloth Face Coverings, Especially in Areas 

among adult Nigerians.

of Significant Community-Based Transmission (2020). Retrieved April 4, 2020 ,

from https://www.cdc.gov/coronavirus/2019 -ncov/prevent-getting-sick/cloth-facecover.html.
How to cite this article: Afocha E. E, Oladele D. A, Ajibaye $\mathrm{O}$ et.al. Knowledge and perception of the risk of contracting coronavirus disease 2019 (COVID-19) among adult nigerians. Int $J$ Health Sci Res. 2021; 11(11): 230-243. DOI: https://doi.org/10.52403/ijhsr.20211128

Appendix I

\section{NIGERIAN INSTITUTE OF MEDICAL RESEARCH}

Research for National Health

COVID-19: Knowledge and risk perception survey

Kindly take about 7 minutes to complete this survey on knowledge and risk perception of the recent COVID-19 disease in Nigerian communities.

\section{Required}

Background and Purpose of Survey: The coronavirus disease 2019 (COVID-19) has become one of the major public health problems of this century, claiming thousands of lives everyday across the globe. The Pandemic has shut down major cities over the world and prompted unprecedented global travel restrictions. Actions such as underrating, stigmatization, nervousness and negative measures to prevent infection affect the battle against this pandemic. Therefore, this survey aims to evaluate knowledge and perceptions on COVID-19 among the adult public in Nigeria so as to provide valuable information for prevention and management of COVID-19 in Nigeria.

Informed Consent: You are invited to participate in the above described survey on knowledge and risk perception to COVID-19. Your participation in this survey is voluntary. The procedure involves filling an online survey that will take about 7 minutes and your responses will be confidential. Clicking on the yes button below indicates that: - You have read the above information - You voluntarily agree to participate in the survey $\bullet$ You are at least 18 years of age

\section{Mark only one oval.}

Yes

No

\section{Socio-Demographic Information}

Age (last birthday) *

\section{Sex}

Mark only one oval.

$$
\text { Female }
$$

Male

\section{Education}

Mark only one oval.

Primary

Secondary

Tertiary

No formal education 
Afocha E. E et.al. Knowledge and perception of the risk of contracting coronavirus disease 2019 (COVID-19) among adult Nigerians.

\section{Employment status}

Mark only one oval.

Employed

Unemployed

Awareness of COVID-19

Have you heard about COVID-19? *

Mark only one oval.

Yes

$\bigcirc$ No

If yes, how did you hear about it? [Mark all that apply]

Check all that apply.

T Radio

T Television

$\lceil$ Newspaper

- Social media

- Health worker

- Place of worship

$\lceil$ Family and Friend

Work place

Knowledge of COVID-19

Coronaviruses are viruses which may cause illness in animals or humans * Mark only one oval.

Yes

No

Don't Know

What are the symptoms of COVID-19 [Mark all that apply] *?

Check all that apply.

Fever

Г Tiredness

Dry Cough

$\lceil$ Sore throat

$\lceil$ Redness of the eyes

- Diarrhoea

- Nasal Congestion/Running nose

weight loss

$\lceil$ Difficulty in breathing

How long does it take before an infected person can develop the disease?

Mark only one oval.

Immediately

1 - 14 days

15 - 18 days

18 days 
Afocha E. E et.al. Knowledge and perception of the risk of contracting coronavirus disease 2019 (COVID-19) among adult Nigerians.

\section{Who is likely to develop serious illness? [Mark all that apply]}

Check all that apply.

「 Older people

$\lceil$ Young people

- Children/Infant

- Persons with underlying medical problems (like high blood pressure, heart problems or diabetes)

\section{How does COVID-19 spread? [Mark all that apply] *}

Check all that apply.

- Can spread from person to person through small droplets from the nose or mouth which are spread when a person with COVID-19 coughs or exhales

- By touching these objects or surfaces, then touching their eyes, nose or mouth

$\lceil$ Breathing in droplets from a person with COVID-19 who coughs out or exhales droplets

From the feaces of someone with the disease

- Could be caught from a person who has no symptoms

$\lceil$ Pets (such as cats and dogs have been infected) could spread the virus

\section{How to protect yourself against COVID-19 Mark all that apply]}

Check all that apply.

- Maintain at least 1 meter (3 feet) distance between yourself and anyone who is coughing or sneezing.

$\Gamma$ Avoid touching eyes, nose and mouth.

$\mp$ Covering your mouth and nose with your bent elbow or tissue when you cough or sneeze.

$\lceil$ Stay home if you feel unwell.

I If you develop symptoms seek medical advice

$\Gamma$ By taking vaccine shot.

$\lceil$ Using of masks.

- Using of masks if caring for individuals who have symptoms, such as cough and fever.

$\lceil$ Regularly and thoroughly clean your hands with an alcohol-based hand rub or wash them with soap and water.

$\Gamma$ Taking hot bath

$\lceil$ Chewing garlic and ginger

\section{How is COVID-19 treated [Mark all that apply]}

Check all that apply.

$\lceil$ Use antibiotics

$\lceil$ Use Chloroquine

- Use HIV drugs

- Use herbal drugs

$\lceil$ No approved treatment currently

\section{Risk Perception}

How much are you worried about COVID-19 disease?

Mark only one oval.

$\begin{array}{lllll}1 & 2 & 3 & 4 & 5\end{array}$

Not Much $\bigcirc \longrightarrow$ Very Much 
If you think of the recent worldwide situation about COVID-19 disease: Do you think that you have a personal risk of acquiring COVID-19 disease

Mark only one oval.

$\begin{array}{llllll}1 & 2 & 3 & 4 & 5 & \\ \text { Highly Likely } \square & \square & & \\ & \square & & \end{array}$

Where/how do you feel most likely at risk of contracting COVID-19 disease [Mark all that apply]

Check all that apply.

「 At work

$\lceil$ In public transport

In public places (School, church etc

$\lceil$ At an airport

- As a patient in the hospital

- At a doctor's office

$\Gamma$ During travel to affected country

- By food imported from affected country

$\lceil$ By other products originating from affected country

Did you change your behaviour because of the COVID -19 outbreak?

Mark only one oval.

$\bigcirc$ Yes

No

If you change your behavior because of the COVID -19 outbreak, what did you do?

[Mark all that apply]

Check all that apply.

$\lceil$ I wash my hand more frequently

「 I avoid contact with people with history of travel in the last 14 days.

$\lceil$ I avoid going to public events (football, theater ...).

$\lceil$ I engaged in precautionary purchases.

What infection control measures have you practiced today? [Mark all that apply] Check all that apply.

$\lceil$ Hand washing with soap and water

$\lceil$ Hand Sanitizer

Face Mask

$\lceil$ Maintaining distance of about one meter

$\lceil$ Drank herbal concoction

Thank you for your time 